\title{
Smart Grid Technology
}

\author{
Keqi Ma \\ School of North China Electric Power University Baoding ,Baoding 071000, China \\ 2870662798@qq.com
}

Key words: Smart Grid, Demand side management, Distributed Generation.

\begin{abstract}
This paper summarizes the connotation and characteristics of smart grid, summarizes the current situation of smart grid technology at home and abroad and the development of smart grid on China's significance, analyzes the conditions of China's development of smart grid, pointed out the construction of smart grid in the network topology, communication systems, , Demand side management, intelligent scheduling, power electronic equipment, distributed power access and other areas need to solve the key technical issues.
\end{abstract}

\section{Introduction}

The greatest technological achievement of mankind in the twentieth century was electrification. From the end of the 19th century to the present, electricity is ubiquitous in the course of human development, and electricity is an indispensable secondary energy for mankind. However, although the power system has been growing since the date of birth, the traditional power system is facing more and more challenges, especially in the global environmental conditions in urgent need of improvement, the development of new energy development today, to achieve sustainable Development, "smart grid" research and construction will be the 21st century development direction, But in general, China is still in a passive tracking stage, and did not form a clear construction ideas. Through the analysis of the concept, characteristics and structure of the smart grid, this paper refers to the foreign examples, and points out that the smart grid is the inevitable result of the economic and technological exhibition.

\section{Research Status of Smart Grid at Home and Abroad}

\subsection{United States}

In February 2003, US President George W. Bush proposed "the grid 2030 plan", pointed out that the construction of modern power system to ensure economic security, while promoting the safe operation of the power system itself. The main contents of the plan are: to provide all users with a high degree of security, reliable, digital power supply services in the country to achieve a reasonable cost, the production process pollution-free, low-carbon power supply, economical and practical energy storage equipment, built superconducting materials Backbone grid. In April 2008, the city of Boulder, Colorado, has been built as the nation's first smart grid city, while more than 
10 states in the United States are starting to promote smart grid development. February 2009, the US President Barack Obama released the "economic recovery plan" proposed a total investment of 11 billion US dollars, the construction of a variety of control equipment can be installed a new generation of smart grid. It is worth mentioning that this session of the US government will smart grid project as its green economic revitalization plan one of the key pillars.

\subsection{Europe}

European smart grid plan called Super Smart Grid, translated as super smart grid. It is a wide area of intelligent transportation network and smart grid combined with a wide area of intelligent network, the possible use of the scope of the EU, North Africa, the Middle East and other countries and regions. The European Council's Energy Green Paper 2006 "European Sustainable, Competitive and Safe Energy Strategy" clearly underscores that Europe has entered a new era of energy, a key technology and development that ensures the quality of power in the EU grid direction. At present, Britain, France, Italy and other countries are accelerating the application of smart grid and change, Italy's local power grid in 2001 has been the first to achieve the intelligent. At the beginning of 2009, the EU-related roundtable further clarified the need to rely on smart grid technology to integrate the offshore wind power of the North Sea and the Atlantic Ocean, southern Europe and North Africa into the European power grid to achieve a leap-forward development of large-scale integration of renewable energy.

\subsection{China}

In the face of the international grid industry so much change, China has no power grid upgrade to the overall strategy of smart grid and promote the commercialization of superconducting grid pilot arrangements, and domestic smart grid technology development is basically a lower international Level, and no one city fully operational smart grid.

East China Power Grid Corporation in 2007 in China took the lead in carrying out the feasibility study of smart grid, and designed the 2008-2030 "three-step" action plan, in 2008 launched a comprehensive high-level scheduling center project for the first breakthrough Stage to work to enhance the scheduling system, the construction of digital substation, improve the power grid planning system, build a unified information platform for the four main business, and strive to complete the 2010 East China Power Grid advanced dispatch center, so that the level of power grid security control, management level overall enhancement.

In the control system of new technologies, by the China Electric Power Research Institute and other units to bear, Xiaoxin Zhou academician as the chief scientist of the national 973 project "to improve the reliability of large-scale interconnection power grid basic research" ,researchers work for the intelligent power system dynamic scheduling and control to provide a basic analysis tools based on intelligent and expert system Power system fault diagnosis and restoration control technology research, developed successfully power grid online operation reliability assessment ,early warning and decision support system platform for the new intelligent grid operation Control development provides a system of research and 
development platform.

\section{Smart grid concept}

There is no definite concept in the grid, and experts from various fields have elaborated the connotation of the smart grid from different perspectives, and it has been refined with the deepening of research and practice. The smart grid is the new "second generation" power grid, which is based on the integrated, high-speed two-way communication network, through the application of advanced sensing and metering measurement technology, equipment technology, control technology and decision support support system technology In order to achieve reliable, safe, high quality, economical, efficient, environmentally friendly and safe use of the grid.

\section{The characteristics of smart grid}

Smart grid mainly has the following characteristics:

1.self-healing and self-adaptation. Real-time control of the operation of the power grid, timely detection, rapid diagnosis and elimination of hidden dangers; in as little as possible human intervention, rapid isolation failure, self-recovery, to avoid large-scale power outages.

2.safe and reliable. To better identify and respond to human or natural perturbations. In the natural disasters, external damage and computer attacks and other circumstances to ensure that personal, equipment and power grid security.

3.cost-effective. Optimize the allocation of resources, improve equipment transmission capacity and utilization; in different regions between the timely scheduling, balance the power supply gap; support the power market competition requirements, the implementation of dynamic floating price system to achieve the optimal operation of the power system.

4. compatible. Both to adapt to large power supply centralized access, but also support the distributed generation of friendly access and large-scale application of renewable energy to meet the power and natural environment, social and economic development of the harmonious development requirements.

5.user-friendly interaction. To achieve intelligent interaction with customers, with the best power quality and reliability of power to meet customer needs. System operation and wholesale, retail electricity market to achieve seamless convergence, and through market transactions to better motivate the power market to participate in the main power grid security management, thereby enhancing the safe operation of power systems.

\section{The important technology involved in the construction of smart grid}

\subsection{Stable and flexible network topology}

The stable and flexible grid structure is the foundation of the future smart grid. China's energy distribution and productivity layout is very uneven, both from the current or in the long run, to meet the economic and social development of the demand for electricity, must take long-distance, large-scale transmission and 
large-scale optimization of the allocation of resources. UHV transmission can improve the transmission capacity, reduce the transmission loss, increase the economic transmission distance, save the channel corridor area, save the project investment, protect the ecological environment also has obvious advantages.

\subsection{Open, standard, integrated communication system}

The smart grid needs the ability to monitor and analyze the current state of the system in real time: both the ability to identify early warning signs of failure, as well as the ability to respond to disturbances that have occurred. Smart grid also need to integrate and integrate enterprise asset management and power grid production operation and management platform, so as to power grid planning, construction, operation and management to provide a full range of information services. Therefore, broadband communications networks, including cables, fiber, power line carriers and wireless communications, will play an important role in smart grids. The development of smart grid put forward higher requirements for network security, which requires special attention. At present, EPRI partners in the United States PowerWec, EEI, NERC and Idaho laboratories are working on information security issues.

\subsection{Intelligent dispatching technology and wide area protection system}

Intelligent dispatch is the inevitable trend of future power grid development, the intelligent of dispatching is a significant expansion of the function of existing scheduling control center. The ultimate goal of scheduling intelligence is to establish a new theory and new technology of network protection and emergency control integration based on wide area synchronization information, coordinate power system component protection and control, regional stability control system, emergency control system, And recovery control system with a multi-channel security line of integrated defense system. Intellectual and other multi-channel security line with a comprehensive defense system. Intelligent scheduling is the core of online real-time decision-making command, the goal is to prevent and control catastrophe, to achieve a large area of chain fault prevention.

\subsection{Renewable energy and distributed energy access}

How to securely and reliably access a variety of renewable energy sources and distributed energy supplies is also a major challenge when developing smart grids. Distributed energy, including distributed generation and distributed energy storage, has grown rapidly in many countries. Distributed power generation technologies include: micro-gas turbine technology, fuel cell technology, solar photovoltaic power generation technology, wind power technology, biomass power generation technology, marine power generation technology, geothermal power generation technology. Distributed energy storage devices include battery storage, superconducting energy storage and flywheel energy storage. Wind energy, solar energy and other renewable energy in the geographical distribution of uneven, and susceptible to weather, the adjustable capacity of the generator is weak, need to have a strong grid, spare enough to support its stable operation of the grid.

\subsection{Decision support and man-machine interface}

Modern power grids require professional, seamless, and real-time application tools to meet the needs of grid operators and managers to make quick decisions. Decision 
support and man-machine interface technology mainly includes visualization tools and systems that can reduce large amounts of data into easy-to-understand visual formats and a variety of solution software systems that need to be provided when system operators operate, and can also be used as a demo board, Advanced control room design and so on.

\section{Summary}

As the national energy and user distribution and the grid situation is different, understanding of countries on the smart grid is not uniform, but the use of modern information technology, control technology to achieve the power grid has become a common consensus.

By the international financial crisis, China's electricity demand temporarily slowed down, which objectively to adjust and optimize the power and energy structure provides favorable conditions and opportunities.

China's development of smart grid is a long-term systematic project, not only to cover the concept of European and American smart grid and scope, but also to strengthen the backbone of power grid construction, that is, to establish a high-voltage power grid for the backbone of the grid at all levels of high coordination Development of smart grid. China's smart grid will lead the international smart grid development trend.

\section{References}

[1].Kai Xie, Yongqi Liu, Zhizhong Zhu. Future-oriented smart grid [J].China Electric Power,2008,41.

[2].Mingjun Wang. Self - healing power grid and distributed power supply [J]. Power grid technology,2007,31. 